\title{
Development Road Map of Library Construction in Vocational Colleges Digital Age
}

\author{
$\mathrm{Na} \operatorname{Lin}^{1, a}$ \\ ${ }^{1}$ Jilin Agricultural University, Changchun, Jilin Province, China \\ a36670921@qq.com
}

Keywords: Digital, Colleges, Libraries, Library construction.

\begin{abstract}
Based on the current situation of Library Automation Construction of University to conduct research on, we made a number of technical, management, funding, quality of personnel and other existing problems were analyzed. Finally, based on the present and future prospects, outlined the prospects for the construction of university library automation to digital library development.
\end{abstract}

\section{Introduction}

With the progress of science and technology, social and economic development, human entered a new era of knowledge economy. Knowledge management theory is the product of this era. As a new management methods and management tools, practical knowledge of the first born in enterprise management, the business community is also currently be the most widely used [1]. The library knowledge management in recent years has been actively exploring the issue, and with the in-depth study of this issue and concern, people gradually began to explore new areas of knowledge management library [1]. On the current, despite their theory is still immature, however, information on knowledge-based library management will become an important part of the future library construction.

\section{The current status of College Library in Knowledge Management}

University Library system has been at the forefront of the national library automation construction. Better Foundation University has completed a computerized library inside the business, and gradually makes their automation systems to integration and network development [1]. There are more than 20 University Library has an international online retrieval terminals. Mature library minicomputer systems or local area network systems are different ways into China Education and Research Network and the Internet [2]. Peking University, Tsinghua University and Beijing University of Posts and library had been built as early as in 1995 the museum network, LAN connection with the museum campus network and INTERNET, to provide various forms reader's rich information services [3].

Lack of unified management, overall planning. National University Library did not establish an administrative, institutional professional functions of having to judge the overall objective of building automation, the development of norms; specific implementation opinions, and there is no development of related laws, regulations, policies, in order to ensure the smooth progress of this work [2]. Universities Work Commission is merely a mass academic organization, only right to make recommendations, no executive power. Do not form a unified planning and management, to monitor implementation [3]. The institutions recognize the leadership, funding and other issues, the central hall failed to play an active role in guiding the construction of electrical automation. So that the museum uninformed, between each other, and do not collaborate, fragmented, redundant construction waste human, financial, and material nor benefit from network construction, resource sharing going.

Database building small scale, low level. Because of the kind of large-scale domestic Library expectations centralized online processing mode of management system is not developed, so the museum are busy establishing their own bibliographic databases and Archive, the school, the museum self-service. Around this way of working, the museum established a local database common database has been built there over simplification (mainly bibliographic information and secondary literature), the degree of standardization is not high, the size of a small general poor, uneven 
development, business low service levels, repeat and other issues [3]. Isolated and backward resource database construction as a direct result of the high cost of library information network construction, out of short cycle, low overall system level, and the development of technology to keep up with the status quo.

Library software system is inconsistent, incompatible, quality is not high. University Library most use of domestic software [3]. And in the absence of domestic software networking conditions no uniform standard, there is no unified planning situation developed. Its establishment principle, the use of language support systems and network environments vary, but the museum has managed systems, resulting in between the systems are not compatible, data resources cannot be shared. On the other hand the system structure, in most cases, the host processing touch-type centralized management system, still character-based interface, the system platform, lack of openness, connectivity on the user interface. Access to and use of literature information resources are still at an experimental stage.

The traditional management concepts behind the development of a modern library. Library Automation Construction of College Library only stay on improving internal operations to focus on improving efficiency without picking up literature search in this [4]. On the other hand, the relationship between automation and networking clear understanding, do not realize that automation is the network foundation, network automation is an inevitable development of this relationship. Thus there is only the immediate building automation, despite the long-term: to focus only on the local and overall neglect of the state.

Changing Ideas and actively seek leadership support at all levels, to improve the library automation environment. Each should seize implicated to assess opportunities for the library, seek the support of school leaders, during the self-assessment of the non-compliance of local, seize the time with the competent school leaders and school leaders were primarily related to the report, from the entire school angle of external influence, inspire school leaders seriously enough in assessing the previous increase investment, improve the hardware equipment, improve the software system to address the lack of equipment, systems and functions suited to the problem of slow Internet speed, accelerate the pace of construction, to achieve promoting Construction with purpose [4].

Changing Ideas and actively seek leadership support at all levels, to improve the library automation environment. The library, seek the support of school leaders, during the self-assessment of the non-compliance of local, seize the time with the competent school leaders and school leaders were primarily related to the report [5], from the entire school angle of external influence, inspire school leaders seriously enough in assessing the previous increase investment, improve the hardware equipment, improve the software system to address the lack of equipment, systems and functions suited to the problem of slow Internet speed, accelerate the pace of construction, to achieve promoting Construction with purpose.

Talent is talent cultivation as the most important automation and information services key. Personnel training are both a long-term primary task [4]. To change the hierarchy ranks high enough level of expertise is not strong phenomenon, there are plans to enrich the library profession, computer applications in engineering and other professional, foreign language proficiency of university graduates to better library ranks. For existing library managers and operational staff, should be taken, such as various forms of professional training course, a variety of training courses and academic seminars, stages in rotation, vigorously popularize the knowledge and skills of library automation: in particular, focus on training systems development, network maintenance and information retrieval staff to meet the demands of library automation construction.

Accelerate the pace of construction of information resources, the right to guide the reader use. Under conditions permitting, should gradually increase the intensity of investment information resources, build their own unique information resource library [3]. At the same time as the main building as the real resources to produce their own bibliographic database, the database directory pages, features database and full-text database of purchase, electronic publications, Internet downloads to the site navigation, selective processing, guidance, give full play to the advantages of resources and effect. 


\section{Accelerate library information management innovation}

Reform of the existing library management system and regime, Library personnel system reform, in order to meet the growing information needs of the knowledge economy era, is imperative. Reform of the existing library management system and the system, the key is to reform the personnel management system. Library personnel system reform in the past is only the emphasis on material incentives and other incentives static, the actual results and the poor. To create a favorable external environment, the introduction of the human spirit, seek a strong spiritual power [6]. Library personnel management system should reflect the people-centered thinking, to meet people's needs and realize human values, the pursuit of human development as the goal, reflecting the humane care of beauty and harmony, in order to stimulate the work of librarians' enthusiasm and creativity. Innovation management system and management innovation system is difficult [5]. Formed institutions under China's planned economy management structure and system, the lack of redeployment of existing staff motivation incentive and restraint mechanisms.

Innovation management tools. Use of computer multimedia technology, network communications technology to provide users with an interdisciplinary, cross-regional, super-time information demand of virtualization services, information resource virtualization and intelligent retrieval [7]. Library as a knowledge and information collection, collation, storage, an important base for the spread of scientific system has become an important link in the chain, has also become an important part of knowledge innovation. The use of advanced information technology, image retrieval based on color, texture and shape and other characteristics based on content analysis of multimedia data transmission and adaptive browse through voice navigation, so that readers roaming in modern library, even the blind can also be blind through voice navigation or a dedicated mouse to "read" text and maps [4].

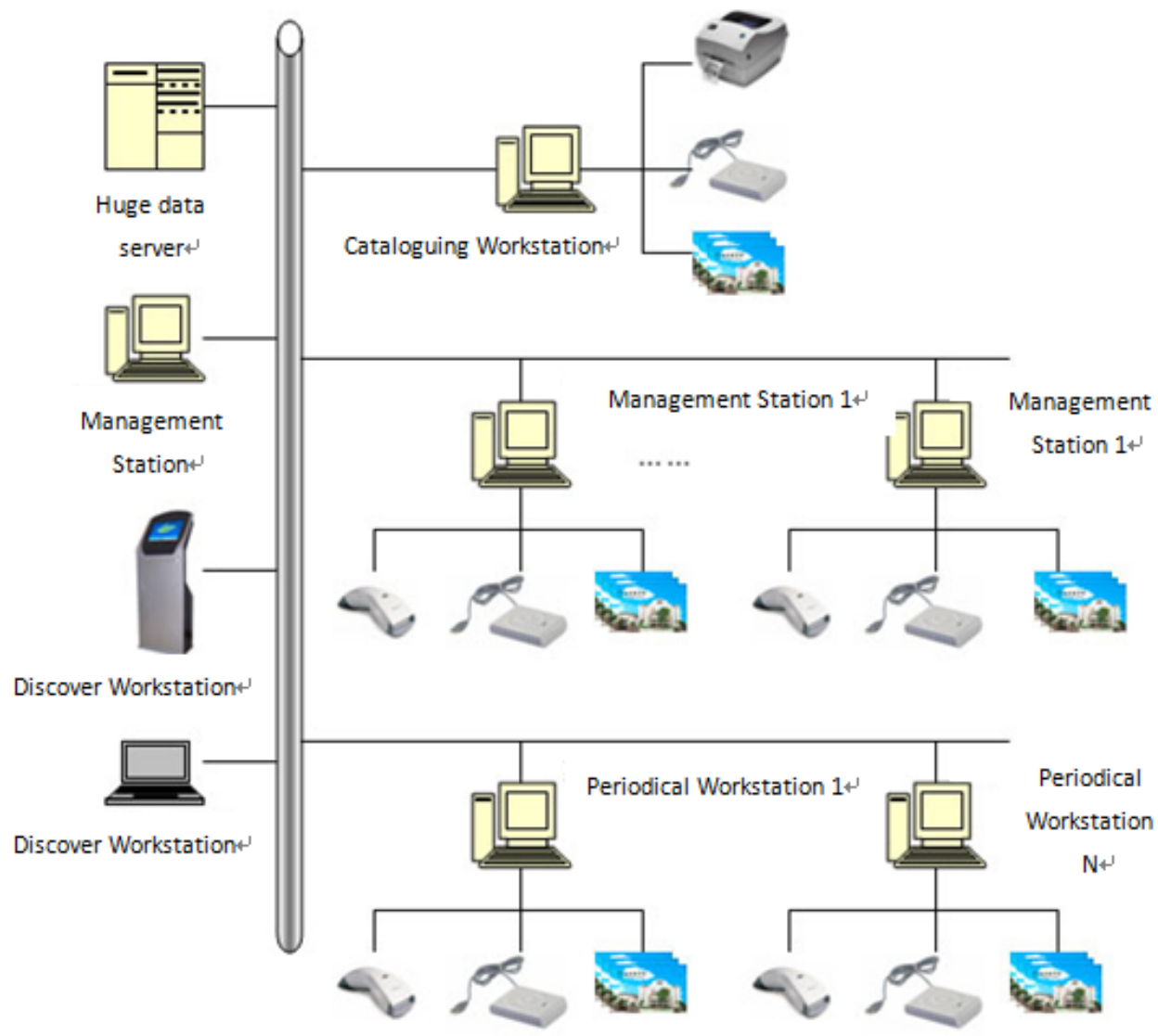

Fig.1 Information Management Library

Innovation and business process reengineering and organizational structure. Management innovations make use of BPR management technology, integration, and reengineering of the library business processes, organizational structure and management model driven by innovation [7]. Business Process Reengineering is the core process management thinking and thought process 
reengineering, stressing break boundaries departments, taking into account the continuity and effectiveness of the process, rather than to the process of production and operation functions for the management objects, is to adapt to the network environment under a new breakthrough enterprise or similar enterprises of all types of social organization management philosophy. Library readers are the main driving force to change the workflow [8]. Business Process Reengineering Management is a personalized management model.

Innovative services for. Service interaction is to "people oriented" transferred from "Book position." Fundamental changes in the concept of people-oriented service Library Service for Readers will occur. In the Internet age, infinite, full of clutter of information around, so that the reader can not help but feel confused and anxious. Readers need libraries provide consolidated, ordered information. Focus on the needs of readers, libraries should be targeted to carry out various forms of service activities [8]. Timely adjustment of service content, form a dynamic management mechanism for demand, adapt to change, it has become necessary for the times [6]. Meanwhile, in the Internet age, the reader is more intense for the individual needs of information, which in individual behavior online and more prominent. Modern readers services to meet the needs of the general reader, we should also seek to answer various questions every reader, library management to carry out innovative research-based information technology perspective.

\section{Summary}

With the rapid development of computer technology, especially the overall popularity of network technology, digital storage and transmission technology, making it the literature of information processing, storage, query, etc. Therefore, the digital library came into being. The advent of digital library provides unprecedented opportunities for new construction and development of the library. In the process of building digital libraries, university libraries how to seize the opportunity to take full advantage of modern high-tech means, will be digitized library resources processing and integration, reasonable collection and use of information and network resources to meet the needs of readers, It is placed in front of us an important issue.

\section{References}

[1] J.Zh. Wu, Chinese Library Outlook 2040, NATIONAL LIBRARY, 2009 (3), pp.28-33.

[2] B.L.Su, Library and Humane Care, Nanning: Guangxi People's Publishing House, 2006,pp220229.

[3] Sh.H. Wang, The presence of the future value of paper documents library. The Library Journal, 2007,pp.42-46.

[4] Z.Zh. Huang, On the new model of the library? Compound Library, Information and Knowledge, 2002, pp. 82-85

[5] H.L. Zhao, Future University Library is sawed, China Culture Daily, 2010, pp. 33-37

[6] F.R. Zhan, Vigorously promote library public service, Promote sustainable development of the library, 2013, pp.55-58.

[7] D.F. Chen, On Hybrid Library oriented personalized service, Information and Documentation, 2012 , pp. 11-16.

[8] Y.N. Chen, Network trend and Library Development, Chinese books tube Sinica, 2006, pp.22-26. 